\title{
Imperatives and commands in Quechua
}

\author{
WILLEM F. H. ADELAAR
}

\section{Preliminary information on Quechua}

Quechua is the denomination of a family of closely related linguistic varieties that are distributed over large areas in western South America and which are spoken, in order of numerical importance, in Peru, Bolivia, Ecuador, Argentina, and Colombia. Local varieties of Quechua are traditionally referred to as 'dialects' (Spanish dialectos), a term which is inappropriate for several reasons. It denotes an expression of the low prestige generally accorded to Quechua by users of the national language (Spanish), and it underscores the difficulty of subdividing this language group into individual languages due to the diffuseness of the boundaries that obtain between its different varieties. The internal linguistic diversity of Quechua is characterized by a mix of gradual transitions ('dialect chains' following the definition in Kaufman 1990) and more or less abrupt divisions attributable to historical splits. Quechua varieties also differ in the amount of contact they have undergone with non-Quechuan languages. There is no universally recognized Quechua standard language, but at least for one variety, Cuzco Quechua, a status of 'correctness' and 'authenticity' has been claimed that may be motivated on historical, but not on linguistic grounds. The internal diversity of the Quechua language family holds evidence of an initial binary split that may have occurred before $500 \mathrm{AD}$, the approximate date of formation of the Wari state in south-central Peru, suggesting an even earlier date for the Quechua protolanguage (Adelaar 2012a, 2012b). The branches resulting from this bifurcation were denominated Quechua I (located in north-central Peru) and Quechua II (all the remaining varieties) in Torero's classification (1964). ${ }^{1}$ All Quechua varieties without

\footnotetext{
${ }^{1}$ In Parker's (1963) classification these groups were denominated Quechua B and Quechua A, respectively. Torero's terminology is more generally used at present.
} 
exception present evidence of a strong Aymaran substrate, which apparently had a formative effect on Proto-Quechua.

\section{(a) General features of Quechua structure and morpho-syntax}

The structure of Quechua is predominantly agglutinating and is characterized by extensive suffixation. Prefixes do not occur at all. Reduplication is frequent in expressive language. Every category of expression (including questions, commands, exclamations, etc.) as well as the articulation of discourse in sentences is covered by affixes, leaving practically no functional space for intonation. In addition, there is also a small amount of fusion as portmanteau affixes are frequently used in verbal inflection. Furthermore, rules of vowel modification may affect the shape of affixes when they occur in a sequence. Formal irregularities in the morphology are rare, but semantic idiosyncrasies (that is, unpredictable meanings of derivational affixes used in combination with specific verbal roots) are common.

The preferred constituent order is verb-final AOV/SV. This order is not always respected, but it is required in non-finite clauses. As a rule, modifiers precede their heads. Exceptions to this rule are relative clauses which contain a nominalized predicate. They can be located after their antecedent in many Quechua varieties. Case affixes and clitics that would follow the antecedent if there were no relative clause are then attached to the nominalized predicate instead.

\section{(b) Word classes}

Verbs and nominals are characterized by distinct morphologies as well as by the shape of their roots. Verbal roots must end in a vowel and are always followed by at least one affix. For most nominals there are no restrictions of this kind. Nominalization (of verbs) and verbalization (of nouns and adjectives) are frequent and play a central role in Quechua morpho-syntax. In addition, there are also ambivalent roots that can function as free nouns and as verb roots at the same time.

Verbs constitute an open class, but the nominal class can be divided into subclasses which are either open (nouns, adjectives) or closed (numerals, personal pronouns, demonstratives, interrogatives, indefinites, etc.). Adjectives can be analysed as a subclass of the nominals with specific morpho-syntactic properties. As an open subclass they can accommodate borrowings. Some adjective-like expressions are verbal in nature, especially terms referring to taste and other sensory categories, Unlike the more common nominal adjectives, they are not accompanied by the copula $k a$ - 'to be' but verbalized by morphological means instead. All Quechua varieties also have a set of adverbs of heterogeneous origin and some grammatical words of limited morphological valency (particles).

In the Quechua personal reference system verbal subject markers and nominal possessive markers are similar in form, though not entirely identical. The lexically 
free personal pronouns stand out in that they are not formally related to any of these personal reference markers.

\section{(c) Grammatical categories for open classes}

Nouns can be marked for person-of-possessor, number (unmarked or plural), and case. In addition there are affixes referring to ownership ('having/not-having') and, in some varieties, degree (mainly with adjectives).

The inflection of finite verbs is organized in three different moods: Indicative (neutral), Potential (also referred to as the 'Conditional'), and Imperative. There is also a fourth, Subordinative mood which includes non-finite verbs that are subject to switch-reference distinctions (same subject versus different subjects).

Verbs in all moods, as well as nominalized verbs, occur with personal reference markers that identify both the subject and, when relevant, a human or humanized object (either direct or indirect). Object marking is just as obligatory as subject marking in that case. It can be complemented but not replaced with a lexical expression outside the verb form. Non-SAP objects are not expressed morphologically. Conservative Quechua varieties as the ones illustrated in this chapter use a four-person system consisting of Speaker (1), Addressee (2), non-SAP (3), and Speaker + Addressee (4). The last category may coincide with first person plural inclusive in a cross-linguistic perspective but is often referred to as the 'fourth person' in the Quechuanist descriptive tradition, so as to highlight its status as a separate, non-derived term of the Quechua personal reference system (cf. Dixon 2012, vol. 2: 203-5, for the polysemy of the term 'fourth person'). This system did not include number in its original form, but most Quechua varieties have developed elaborate number marking which can apply to the subject, as well as to the object. Number marking varies considerably between the Quechua varieties and is evidently of recent origin.

Tense distinctions are semantically well-defined and elaborate (between five and eight tenses according to variety). They are limited to the Indicative and, to a lesser extent, the Potential mood, which has only two tenses (Present and Past). Habitual Past, Perfect and Mirative (Sudden Discovery) are treated as Indicative tenses. As we shall see, Imperative tense (Present versus Future) is a matter of debate. Nominalized verbs are subject to a relative tense distinction (Realized versus Prospective).

Aspect is formally and functionally separate from tense and can combine with any tense, mood, or nominalization. Quechua I varieties have developed structured aspect systems including mutually exclusive categories such as Progressive and Perfective. Further non-derivational categories are Speaker-orientation ('Ventive' or 'hither', etc.), Limitative ('Diminutive'), and Beneficiary. Non-derivational verbal morphology is not used for the creation of new lexical items.

Finally, verbal derivation comprises a large amount of affixes with multiple and heterogeneous functions (different types of valency-change, reflexive and reciprocal, 
state and continuation, assisted action, space and direction, movement back and forth, multiple objects, repetition, conative, inceptive, interrupted action, noncontrol, different sorts of pragmatic usage, etc.). As indicated before, idiomatic fusion of verbal roots with derivational affixes is frequent and an important source of lexical innovation in Quechua.

\section{(d) Grammatical categories for all classes}

All Quechua varieties have a set of sentential or independent affixes, often referred to as 'clitics'. They behave like affixes from a phonological point of view and can be attached to the final element in a sentence constituent regardless of its word-class. They may indicate validation (Evidentials), interrogation, negation, topic, contrast, sequence, inclusion ('also', 'even'), completion ('already'), and anticipation ('still').

There are also some true clitics which play a role in recently identified cases of shared knowledge interaction between speaker and addressee (Hintz, in press). Clitics are also used for emphasis, in tag questions, pleas for corroboration, etc.

\section{(e) Transitivity classes of verbs}

Quechua has a nominative-accusative structure. It has no ergative features whatsoever. Whereas subjects remain unmarked, direct objects are obligatorily marked for Accusative case, except when immediately preceding a nominalized verb. Quechua verbs appear to be insensitive to the transitive/intransitive distinction, as none of the usual morpho-syntactic criteria necessary for establishing such a distinction seems to work. Many non-derived verbs can have both transitive $(S=A)$ and intransitive $(\mathrm{S}=\mathrm{O})$ interpretations without any formal distinction (cf. English 'to break', 'to turn'). In transitive constructions there is no formal difference between verbs with a non-SAP object and verbs with non-identified or irrelevant objects (antipassive interpretation). In line with the limited function of the transitivity parameter, there is no morphological passive, nor any syntactic construction fulfilling that role. ${ }^{2}$ Morphological derivations including those that commonly function as transitivizers (Causative, Applicative) can be applied to any verb regardless of its inherent transitivity status.

\section{(f) Marking of grammatical relations}

Grammatical relations are marked by nominal Case, attached at the end of a noun phrase. Only subjects, nominal complements of a copula verb, and direct objects or goals that immediately precede a nominalized verb are not marked for Case. The

\footnotetext{
${ }^{2}$ As is the case with most features of Quechua structure, the reduced status of the (in)transitivity distinction is shared with the Aymaran languages (cf. Cerrón-Palomino 2008).
} 
function and semantic interpretation of case markers are straightforward and predictable. Stacking of case markers is common, and several of them appear to have originated from combinations of other case markers.

\section{(g) Clause types}

Only main clauses can contain a finite verb. As a rule, copula verbs with a non-SAP subject are omitted unless they contain relevant morphology that cannot be expressed otherwise. When copula verbs are omitted the predicate consists of the nominal complement alone.

Subordinate clauses are formed on the basis of non-finite verbs in the Subordinative mood and may function as con-verbs, temporal or causal clauses. Clauses constructed with a nominalized verb, followed or not by a case marker, are frequent. Most relative clauses belong to this category.

\section{Nature of the sources}

The data presented in this chapter were selected from varieties of each of the two main Quechua branches that are spoken in the Andes of Central Peru. North Junín Quechua (or Yaru), a Quechua I variety, is taken as the point of departure for the presentation of the data. Most examples are from Tarma Quechua, a sub-variety of North Junín Quechua. When relevant, data from other Central Peruvian varieties (QI Ancash, QI Huancayo, QI Pacaraos, and QII Ayacucho) are included. All these varieties are conservative and exhibit roughly the prototypical structure of the Quechua family by default of relevant innovations. The data are from the author's fieldwork in the 1970 s and 1980s on North Junín (Tarma) and Pacaraos Quechua (Adelaar 1977, 1987), and from published literature on other varieties: Cerrón-Palomino (1976) on Huancayo, Parker (1976) on Ancash, and Soto Ruiz (1979) on Ayacucho Quechua.

\section{Expression of imperatives}

For the expression of commands Quechua has a dedicated Imperative mood with basic forms for $2 \mathrm{nd}, 3 \mathrm{rd}$, and 4 th person subject, as shown in Table 1.

TABLE 1. Basic forms of the Imperative in Quechua

\begin{tabular}{|l|l|l|}
\hline 1st & & \multicolumn{2}{l|}{} \\
\hline 2nd & -y & rima-y 'speak!' \\
\hline 3rd & -čun & rima-čun 'let him/her speak!' \\
\hline 4th & -šun & rima-šun 'let us speak!' \\
\hline
\end{tabular}


TABLE 2. Further forms of the Imperative in Quechua

\begin{tabular}{|l|l|l|}
\hline 2nd > 1st & -ma-y & maqa-ma-y 'beat me!' \\
\hline 3rd > 1st & -ma:-čun & maqa-ma:-čun 'let him/her beat me!' \\
\hline 3rd > 4th & -ma:-šun & maqa-ma:-šun 'let him/her beat us!' \\
\hline 3rd > 2nd & -šu-nki & $m a q a-\check{u} u-n k i \quad$ 'let him/her beat you!' \\
\hline
\end{tabular}

In the early literature on Quechua the non-canonical 3rd person form -čun was not immediately recognized as part of the Imperative mood. It contains an element $-n$, which is identical in form to the Present tense ending for 3 rd person subject. Parker (1969: 30), for instance, did not incorporate -čun in the Imperative paradigm but interpreted the element $-\check{c} u$ - as an Injunctive suffix with a limited distribution.

The 4th person (first person plural inclusive) Imperative form is identical to the 4th person Future tense form. Its parallel interpretation as an Imperative form was recognized at a relatively early stage.

The 2nd person form $-y$ is identical to the ending of the Infinitive nominalization (as in rima-y 'to speak'). Chances of confusion are scarce due to contextual information and the presence of affixes pertaining to nominal morphology, because Infinitives behave like nouns. A historical relation between the Imperative and Infinitive endings cannot be excluded but remains highly speculative as it would take us beyond the stage of Proto-Quechua.

The affix $-y$ is also a marker for 1 st person subject in the Quechua II dialects. This affix is now restricted to positions in the paradigms in which ambiguity with the Imperative is excluded. In other environments, it has been replaced by a suffix -ni.

As shown in Table 2, the Imperative paradigm has further forms that in addition to the subject encode a non-SAP object. Three of these forms, 2 nd $>1$ st, $3 \mathrm{rd}>1 \mathrm{st}$, and $3 \mathrm{rd}>4$ th, contain the element $-m a($ :)- (primary meaning 1st person object). In most dialects there is no dedicated ending for $3 \mathrm{rd}>2 \mathrm{nd}$. The ending $-\mathrm{s}^{u} u-n k i$ is the same as the one used for Present Tense and Future. ${ }^{3}$

\section{Imperative and Future tense}

In order to establish the independent character of the Imperative it is necessary to also look at the Future tense paradigm (Table 3). There is a considerable overlap between the two paradigms. The use of Future tense is obligatory for any statement referring to an event expected to occur after the moment of speaking.

\footnotetext{
${ }^{3}$ In Ancash Quechua (QI) the 3rd > 2nd ending has been restructured to -šu-y (Parker 1976).
} 
TABLE 3. Quechua future tense paradigm

\begin{tabular}{|l|l|l|}
\hline & Future Tense & Imperative \\
\hline 1st & -šaq & - \\
\hline 2nd & -nki & -y \\
\hline 3rd & -nqa & -čun \\
\hline 4th & -šun & -šun \\
\hline 1st $>$ 2nd & -šay(ki) ${ }^{\text {a }}$ & - \\
\hline 2nd > 1st & -ma-nki & -ma-y \\
\hline 3rd > 1st & -ma-nqa & -ma:-čun \\
\hline 3rd > 2nd & -šu-nki & -šu-nki \\
\hline 3rd > 4th & -ma:-šun & -ma:-šun \\
\hline
\end{tabular}

${ }^{a}$ In North Junín Quechua the element -ki of the ending -šay( $\left.k i\right)$ is optionally present in word-final position and silent elsewhere. When $-k i$ is not pronounced in word-final position the ending is realized as -šáy with stress on the final syllable. Normally, stress is located on the penultimate syllable.

Already in early colonial sources (Gonzales Holguín 1607: 85) Future tense was recognized as a delayed alternative for the plain Imperative, a 'Future imperative', and it is still frequently used with that function. Nevertheless, Future tense forms can also occur in questions, and they combine freely with affixes of the Validator or Evidential set $-m(i)$ (Assertive), $-\grave{s}(i)$ (Reportative), and $-\hat{c}(i)$ (Conjectural), in particular, with the Assertive marker $-m(i)$, which in this case denotes conviction or certainty rather than any evidential meaning. Imperative forms do not occur in questions and do not take validators. Accordingly, one may assume that the use of Validators/Evidentials would also be blocked with Future tense forms that are used in commands, but that is not the case. The Assertive Validator can be used in connection with Future tense forms denoting command.

(1) aywa-mu-nki čay-/ĉu lapa-nči mika-paku-na-nči-pa

go-VEN-2S:FUT that-LOC all-4POSS eat-SB-NOMZ-4S-BEN

You must come so that we can all have something to eat there!

(2) ama- $m$ maqa-wa-nki-ču-qa tayta

NEG-VAL beat-10-2S:FUT-NEG-CONTR sir

But you are not going to hit me, sir! (Don’t you dare!) (Soto Ruiz 1979: 331)

(3) supay-pa wača-sqa-n čutu, ama- $m n^{y}$ uqa-ta-qa

(Soto Ruiz 1979: 331)

kuti-pa-wa-nki-ču

devil-GEN give.birth-NOMZ-3POSS EXPL NEG-ASS me-ACC-TOP

return-APPLIC-1O-2S:FUT-NEG

!!!EXPLETIVE!!! born from the Devil! You are not going to talk back to me! 
It may be tempting to further assign Imperative status to the 1st person subject Future forms that are missing from the Imperative paradigm, considering the overlap in the rest of the paradigm, but there is no evidence that these 1st person forms occur in the typical Imperative environments in which the use of Validators/Evidentials is excluded. This is a good reason not to consider them as possible Imperatives (although further research is needed).

\section{Negative commands}

Negation is expressed at the sentence level by the combination of a negative adverb (mana, ama) and the sentential affix -ču. In negative statements and commands the sentential affix cannot be attached to the negative adverb itself, as its location reflects the scope of the negation. In subordinate clauses, nominalized clauses, and other units below the sentence level the same negative adverbs are used without the affix -čcu. As a rule, mana is found in declarative statements, whereas ama is used for negative commands, suggestions, exhortations, admonitions, intentions, etc.

(4) mana-m mayla-ku-nki-ču

NEG-VAL wash-REFL-2S:FUT-NEG

You will not wash yourself.

(5) ama rima-pa-y-ču

PROHIB speak-APPLIC-2S.IMP-NEG

Do not talk to him!

(6) ama-m huk-huk-ta-qa aw ni-nki-ču

PROHIB-VAL one-one-ACC-TOP yes say-2S:FUT-NEG

You should not say 'yes' to everyone.

As can be seen in (6), the use of ama is not incompatible with the Assertive validator $-m(i)$.

\section{Prohibitive adverb ama}

In negative commands constructed with the Imperative the prohibitive adverb ama is the only option ((5), (7)); mana is excluded.

(7) ama lagi.ku-čun-ču

PROHIB worry-3S:IMP-NEG

He/she should not worry!' (Let him/her not worry!)

Reversely, the difference in use between ama and mana does not coincide with the boundary between negative commands and statements. Ama can be used in any construction that denotes an overtone of suggestion, recommendation, admonition, reproach, etc. In this way, the choice of the prohibitive adverb adds an extra 
dimension which makes it possible to introduce notions of command in nonimperative contexts. In (8) a prohibition is expressed by means of the Past Potential (irrealis) and in (9) a Future tense is used.

(8) ama wila-nki-man-ču ga-ra

PROHIB warn-2S-POT-NEG be-PAST:3S

You should not have warned him.

(9) ama aywa-šaq-ču ni-:-mi

PROHIB go-1S:FUT-NEG Say-1S-VAL

I think I should rather not go. (I say I would better not go.)

(10) ama kaču-su-na-yki-paq tanta-ta qu-nki al ${ }^{\mathrm{y}} q u-m a n$

PROHIB bite-INV-NOMZ-2S-BEN bread-ACC give-2S:FUT dog-ALL

You will/must give bread to the dog so that it would not (Soto Ruiz 1979) bite you.

The prohibitive adverb ama is also found in the expression:

(11) ama čay-nuy-qa ka-la-y-ču

PROHIB that-SEMB-TOP be-DIM-2S:IMP-NEG

Don't be like that! (Don't be so mean!)

The expression in (11) corresponds to Andean Spanish ¡no seas así! by which an asker seeks to anticipate an expected refusal by his addressee. The parallel expression in Ayacucho Quechua is ama hina ka-y-ču 'don't be like that!' It can be transposed into a subordinate clause ama hina ka-spa or ama hina ka-spa-yki ('(you) not please being so mean'), which has acquired the general meaning of 'please!', 'I beg you'. In this way the prohibitive adverb has come to modify a non-finite subordinate verb. Example (12) shows that ama retains its illocutionary effect even in such a reduced syntactic environment.

(12) ama hina ka-spa haywa-yka-mu-wa-y waqta-yki-pi ka-q qata-ta

PROHIB thus be-SUBORD:SS hand.over-ATT-VEN-1O-2S:IMP side-2POsS-LOC

be-AG blanket-ACC

'Please hand me the blanket that is beside you!'

(Soto Ruiz 1979)

\section{The copula construction in an imperative environment}

Within a copula construction (Nominal complement $+k a$ - 'to be'), the Nominal complement comes first and hosts the sentential affixes if any. The Copula verb 'to be', if expressed at all, does not take any sentential affixes. This state of affairs holds for all non-imperative finite environments. However, in Imperative clauses, the Copula verb is always expressed and does receive the sentential affixes if any. As a 
rule, none of the latter remains on the Nominal complement (for a rare exception see (11)). This divergent behaviour of the copula construction in Imperative utterances suggests that the Imperative endows the verb 'to be' with a more active and more deliberate meaning than it has in non-imperative sentences.

(13) mana-m suwa-ču ka-nki

(NJQ constructed example) NEG-VAL thief-NEG be-2S

You are not a thief.

(14) ama suwa ka-y-ču

(NJQ constructed example) NEG thief be-2S:IMP-NEG

Don't be a thief!

\section{Grammatical categories of imperatives}

The Imperative mood in Quechua is compatible with categories of Aspect and Number as any other mood. There are no restrictions that are specific for the Imperative. Nevertheless, there may be some semantic effects associated with Aspect. For instance, the presence of a Perfective Aspect marker - $r u$ - may imply rudeness because it incites the addressee to hurry up. ${ }^{4}$ Also in the imperative context, the presence of a Progressive Aspect marker is an invitation to carry on with an action already begun or to start an action before the speaker is able to join it. Some Quechua dialects (Cajamarca, Huancayo) have different Progressive Aspect markers in order to distinguish between continued action and anticipated action.

As we have seen, the Imperative mood is incompatible with Tense and Evidentiality. The only possible tense distinction is related to the use of Future tense in lieu of Imperative (see \$4), in which case the Imperative mood would function as an immediate imperative and Future tense as a delayed imperative. As we have seen, it is not certain that such Future tense forms can be analysed as Imperatives. Evidential markers are typically absent from Imperative clauses but not from Future tense expressions with an imperative connotation. Other sentential affixes combine with the Imperative without any problem.

Quechua has no gender, nor voice distinctions. The interference with Imperative is null. However, one verbal derivational category, Non-control $-k a(:)-$, refers explicitly to actions performed outside one's own will (e.g. iški-ka(:)- 'to lose one's balance and fall', from iški- 'to fall'). A combination with the Imperative seems unlikely, although specific research is needed to corroborate this.

\footnotetext{
${ }^{4}$ By contrast, Cerrón-Palomino (1976: 180, 205) reports that the presence of a Perfective Aspect marker, eductivo ('Outward motion') in the author's terminology, can indicate urgency but also produce an attenuating effect in Huancayo Quechua (QI). Of course, it may be that the secondary effects of the Aspect/Imperative combination differ from region to region. Further research is evidently needed.
} 
In a similar way it is unlikely that the Imperative would be combined with the subclass of verbal adjectives that refer to permanent material qualities ( $p u \check{q} q u$ - 'to be sour', aya- 'to be spicy', etc.) and other verbs referring to permanent material qualities. The Imperative cannot be combined with impersonal verbs, such as those referring to weather conditions (tamya- 'to rain', rašta-, rawu- 'to snow', etc.), although this may have been different in pre-Hispanic times.

\section{Politeness}

The impact of an Imperative command in North Junín Quechua can be attenuated by the use of specific verbal derivational affixes. The suffix -rku-/-rgu- primarily functions as a Directional affix indicating 'Upward motion'. In addition, it has developed a secondary function as a social enabler. By using it the speaker asks for the addressee's permission or consent and, if possible, his active participation. Hence the Spanish translation 'con (su) permiso'. Another Directional affix $-y(k) u$ - 'Inward motion' has acquired a secondary function as a plea for attention in requests. Both are frequently used in Imperatives, but not exclusively.

(15) upya-ku-rgu-šun

drink-REFL-SE-4S:IMP

Let us have a drink together! (If you feel like it.)

(16) šayu-yu-y

stop-ATT-2S:IMP

Please stop for a moment!

Another derivational affix frequently used in Imperative commands is the Conative -ĉa:ri-.

(17) rima-ĉa:ri-y

speak-CON-2s:IMP

Talk to him! (Why don't you try?)

The Conative is frequently used with the pre-imperative element ma(:) (see below).

\section{Pre-imperatives}

The element ma: (QI) or ma (QII) is probably found in all Quechua varieties. It introduces commands, although not exclusively. It denotes a strong incitation to perform an action, sometimes with the connotation of an experiment (English 'come on!' 'let us see!'), but its use is not necessarily impolite.

(18) ma: šargu-rgu-r kanan wila-ba:-ma-y yaĉa-či-nqa-q-ta come.on! stand-SEQ-SUBORD:SS now tell-APPLIC-1O-2S:IMP learn-CAUS-NOMZ1S:2O-ACC

Come on, stand up and now tell me what I have taught you! 
Example (18) also shows how a series of actions in a command is encoded. Only the main verb is in the Imperative form in this case, whereas the subordinate one has the shape of a con-verb.

\section{Special imperatives}

Another ubiquitous element associated with Imperatives is aku ( akuči, akuču) (Ayacucho Quechua haku). It represents an exhortation to get moving (Spanish ¡vamos!). Aku can be used alone or as a substitute for an Imperative verb of motion in the $4^{\text {th }}$ person (1st person Inclusive), followed by an Agentive (nominalized) verb that indicates the purpose of the motion.

(19) aku urya-q

let.us.go work-AG

Let us go work!

In Ayacucho Quechua and other southern Peruvian varieties it is also frequently followed by a finite verb in the 4 th person Imperative.

(20) haku ripu-sun

let.us.go go.away-4s:IMP

Come on, let us go away (for good)!

\section{Post-verbal clitics}

The effect of an Imperative can be strengthened or attenuated by the addition of clitics at the end of the Imperative form. Such clitics may indicate an emotional involvement of the speaker or refer to interpersonal interaction (shared knowledge). They usually exhibit a divergent stress pattern. It is a domain that has only recently begun to be investigated for the Ancash varieties of Quechua (Hintz, in press). Quechua dialects vary widely in the clitics they use, and these are seldom restricted to the Imperative. North Junín Quechua uses a clitic ar with Imperatives. It denotes resignation or reassurance.

(21) urya-y=ár muna- $\mathrm{r}-\mathrm{q}[\mathrm{a}]=$ =ár o sino: ama-si work-2S:IMP=RESIG want-SUBORD:SS=RESIG or otherwise PROHIB-ADD Work if you want, or else you don't!

Pacaraos Quechua, an archaic Quechua I dialect, frequently uses an emphatic clitic $a$ : attached to the Imperative form. It is not exclusive for imperative commands.

(22) rima-šun=a: yaĉa.ku-y-á:

speak-4S:IMP=EMPH learn-2s:IMP=EMPH

Let us talk! Learn! 


\section{Imperative in quotations}

Imperatives are frequently used in direct discourse.

(23) kasara:-šun ni-r inga: ${ }^{y} \mathrm{u}$-ta rura-ru-ra

marry-4S:IMP say-SUBORD:SS deceit-ACC do-PERF-PAST:3S

Saying 'let us get married!' he cheated them.

\section{Vocatives}

A dedicated Vocative is found with nouns referring to close kin and persons of respect in southern Peruvian Quechua (including Ayacucho). It consists in the addition of an affix $-y$ with stress assignment to the preceding vowel. If the word ends in a consonant the vowel preceding that consonant becomes stressed, e.g. in mamáy 'mother! Madam!' and sen ${ }^{y}$ ór 'Sir!'

\section{Imperative strategies}

Quechua has several strategies to express commands without having recourse to the dedicated Imperative. We can only cite a few examples. A common strategy is the use of the Present Potential, usually in combination with a Perfective Aspect marker in order to enhance the element of threat.

(24) supay=aba-ru-nki-man ${ }^{5}$

devil=carry-PERF-2S-POT

May the Devil carry you away! (May you rot in Hell!)

An apprehensive construction in Quechua is expressed by the same technique, except that the Potential form is followed by a sentential suffix -taq, which in other environments indicates a contrast between parallel sequences (among other things). Despite the intention of a negative admonition proper to this construction no grammatical negation is involved at all.

(25) yata-ru-nki-man-taq

touch-PERF-2S-POT-CONTR

Be careful not to touch it!

A deontic construction involving the Future (non-realized) nominalization in -na provides the speaker with still another way to express a command, as can be seen in the following example from Pacaraos Quechua.

\footnotetext{
5 The expression supay=aba- ('devil-carry') is a rare case of a compound verb. Its common interpretation is 'to be carried away by the Devil', 'to rot in Hell'.
} 
(26) kicwa-kta-m rima-na

Quechua-ACC-VAL speak-FUT:NOMZ

One has to speak Quechua!' (Spanish ¡Hay que hablar quechua!)

\section{A final word}

The function of command and prohibition in Quechua is covered by a dedicated Imperative mood, which cannot be combined with sentential affixes referring to validation and evidentiality. Competing verbal categories, such as Potential mood and Future tense, can be used in contexts that imply a command but they lack the typical imperative properties that exclude validation and evidentiality. A remarkable role is reserved for the Prohibitive adverb ama, which operates as a lexical instrument introducing a connotation of command in syntactic environments that are not otherwise associated with the Imperative.

\section{Acknowledgements}

The research leading to this chapter has received funding from the Australian Research Council and from the European Research Council under the European Union's Seventh Framework Programme (FP7/2007-2013) / ERC grant agreement no. 295918.

\section{References}

Adelaar, Willem F. H. 1977. Tarma Quechua: Grammar, texts, dictionary. Lisse: Peter de Ridder Press.

Adelaar, Willem F. H. 1987. Morfología del quechua de Pacaraos. Lima: Universidad Nacional Mayor de San Marcos, Facultad de Letras y Ciencias Humanas.

Adelaar, Willem F. H. 2012a. 'Modeling convergence: Towards a reconstruction of the history of Quechuan-Aymaran interaction' Lingua, 122(5): 461-9.

Adelaar, Willem F. H. 2012b. 'Cajamarca Quechua and the expansion of the Huari state', pp. 197-217 of Archaeology and Language in the Andes: A cross-disciplinary exploration of prehistory, edited by Paul Heggarty and David Beresford-Jones. Proceedings of the British Academy, Vol. 173. Oxford and New York: Oxford University Press.

Cerrón-Palomino, Rodolfo M. 1976. Gramática Quechua Junín-Huanca. Lima: Instituto de Estudios Peruanos.

Cerrón-Palomino, Rodolfo M. 2008. Quechumar: Estructuras paralelas del quechua y del aimara. La Paz: Universidad Mayor de San Simón, ProeibANDES and Plural editors.

Dixon, R. M. W. 2012. Basic linguistic theory: Further grammatical topics. Oxford: Oxford University Press.

Gonzales Holguín, Diego. 1607. Gramática y arte nueva de la lengua general de todo el Perú llamada lengua qquichua o lengua del Inca. Lima: Francisco del Canto. 
Hintz, Daniel J. In press. 'The evidential category of mutual knowledge in Quechua', to appear in Lingua.

Kaufman, Terrence S. 1990. 'Language history in South America: What we know and how to know more', pp. 13-73 of Amazonian Linguistics: Studies in lowland South American languages. Austin: University of Texas Press.

Parker, Gary J. 1963. 'La clasificación genética de los dialectos quechuas', Revista del Museo nacional (Lima) 32: 241-52.

Parker, Gary J. 1969. Ayacucho Quechua grammar and dictionary. The Hague and Paris: Mouton.

Parker, Gary J. 1976. Gramática quechua Ancash-Huailas. Lima: Ministerio de Educación and Instituto de Estudios Peruanos.

Soto Ruiz, Clodoaldo. 1979. Quechua, manual de enseñanza. Lima: Instituto de Estudios Peruanos.

Torero, Alfredo. 1964. 'Los dialectos quechuas', Anales científicos de la Universidad Agraria de La Molina (Lima) 6(3-4): 291-316. 